\begin{tabular}{|c|c|}
\hline & $\begin{array}{c}\text { International Journal of Current Research } \\
\text { and Academic Review }\end{array}$ \\
\hline & $\begin{array}{r}\text { ISSN: 2347-3215 } \text { (Online) }:, ; \mathbf{V} \\
\text { Journal homepas }\end{array}$ \\
\hline
\end{tabular}

doi: http://dx.doi.org/10.20546/ijcrar.2017.502.008

\title{
Emerging Role of Medical Informatics: An Outlook
}

\author{
A. Suguna and A. Surekha* \\ Department of Community Medicine, MGMC \& RI, Pondicherry \\ *Corresponding author
}

\section{Introduction}

Medical Informatics is the interdisciplinary study of the design, development, adoption and application of ITbased (Information Technology based) innovations in healthcare services delivery, management and planning. Informatics gained widespread adoption mainly with electronic health records. The widespread adoption of medical informatics allowed healthcare providers secured and quick access to pertinent data on a patient. Clinical informatics is an emerging discipline in medical informatics with the goal of advancing the field in improving healthcare.

Health has been identified as one of the key sectors that can benefit from computer technology and telecommunications. Population-based approaches have the potential to prevent 70 percent of premature deaths through measures that target underlying risks, such as tobacco, drug, and alcohol use; diet and sedentary lifestyles; and environmental, occupational, and infectious risk factors. Medical informatics has an important role in such population-based approaches.

The National Cancer Institute in U.S is creating a new Cancer Informatics Infrastructure (CII) where by replacing today's paper processes, the CII will speed the translation of exciting basic research discoveries to the practice of medicine at the patient's side. Once in place, this new infrastructure will bring profound changes in the practice and art of cancer care. While in India, the Ministry of Health and Family Welfare, Government of
India has set up the National Health Portal in pursuance to the decisions of the National Knowledge Commission, to provide healthcare related information to the citizens of India and to serve as a single point of access for consolidated health information.

\section{Healthy people 2010}

It defines health literacy as "the degree to which individuals have the capacity to obtain, process, and understand basic health information and services needed to make appropriate health decisions. The most important purpose of health informatics is to deliver the effective health care to patients by increasing health literacy. It also includes technology advancement in drug discovery, dentistry and pharmacy. Public Health Informatics is the application of informatics in areas of public health, including surveillance, prevention, preparedness, and health promotion. However, the field of informatics also serves other facets of public health including emergency response, environmental health, nursing, and administration. The informatics perspective can provide insights and opportunities to improve ongoing elements of any public health surveillance system like

\section{Planning and system design}

Data collection, data management and collation, analysis, interpretation and dissemination

The move from manual reporting from traditional data sources to automated data collection from novel data 
sources has suddenly begun in earnest, and public health agencies will need to keep pace or risk gradually losing old systems of health event ascertainment and failing to achieve the benefits of new electronic reporting. To conclude-It is time to look into organizational, economic, social, clinical impact, ethical and costbenefit aspects of IT applications in health care. It's also time to focus on development and use of interoperable information systems for public health functions such as bio-surveillance, outbreak management, electronic laboratory reporting and prevention by enhancing health literacy through medical informatics.

\section{References}

United States National Library of Medicine

A report from the U.S. Public Health Service's Data Policy Coordinating Committee

National Health Portal, India: www.nhp.gov.in

U.S. Department of Health and Human Services, Office of Disease Prevention and Health Promotion. Healthy People 2010 Available at http://www.healthypeople.gov/Publications/

\section{How to cite this article:}

Suguna, A., and Surekha, A. 2017. Emerging Role of Medical Informatics: An Outlook. Int.J.Curr.Res.Aca.Rev. 5(2), 61-62. doi: http://dx.doi.org/10.20546/ijcrar.2017.502.008 